\title{
Accuracy of the CMORPH satellite-rainfall product over Lake Tana Basin in Eastern Africa
}

\author{
AlEMSEGEd TAMIRU HAILE $^{\mathrm{B}}$, FANG YAN $^{\mathrm{A}}$, EMAD HABIB $^{\mathrm{A}}$ \\ ${ }^{A}$ Department of Civil Engineering \\ University of Louisiana at Lafayette, Lafayette, LA 70504, USA \\ ${ }^{B}$ International Water Management Institute, P. O. Box 5689, Addis Ababa, Ethiopia.
}

Submitted to Atmospheric Research

First submission: 30 April 2014

(*) Corresponding Author: Alemseged Tamiru Haile, International Water Management Institute, P. O.

Box 5689, Addis Ababa, Ethiopia. Email: A.T.Haile@cgiar.org; alemsegedtamiru@yahoo.com 


\begin{abstract}
In this study, we assessed the accuracy of rainfall occurrence, amount and distribution over the Lake Tana basin in Ethiopia, Eastern Africa, as represented in the NOAA satellite-based Climate Prediction Center Morphing technique (CMORPH) rainfall product. This analysis is carried out at high spatial and temporal resolutions ( $8 \times 8 \mathrm{~km}^{2}$ and daily) using observations from rain gauges as a reference for the period covering January 2003 to December 2006. Graphical comparisons and several statistical metrics such as bias, correlation coefficient, and standard deviation of rainfall differences are used to perform the evaluation analysis. Spatial maps of these statistical metrics were developed to assess the spatial dependency in the CMORPH accuracy. The bias is decomposed into different components, hit, missed, and false, in order to gain additional insight into the possible sources of systematic deviations in CMORPH. Overall, CMORPH was able to capture the seasonal and spatial patterns of rainfall over the basin, but with varying degrees of accuracy that depend on topography, latitude and lake-versus-land conditions within the basin. The results show that CMORPH captured rain occurrence relatively well in both wet and dry seasons over the southern part of the basin but it significantly overestimated those over the lake and its southern shore. The bias of CMORPH in the study area is characterized by seasonal and spatial variations (-25 to $30 \%$ in wet season and -40 to $60 \%$ in dry season). False as well as missed rains contribute significantly to the total rainfall amounts over the basin. Significant levels of the differences are observed at the daily resolution of CMORPH. The relation between CMORPH and gauge rainfall amounts is stronger (correlation mostly $>0.4$ ) in the wet season than in the dry (mostly <0.4).
\end{abstract}

Keywords: CMORPH; Rainfall; Blue Nile; Remote sensing; Accuracy 


\section{Introduction}

Rainfall is a major component of the water cycle and hence understanding of its spatial and temporal distribution is of immense importance. Particularly, rainfall plays a pivotal role in the livelihood of many African countries that predominantly rely on rainfed agriculture. Nowadays, we have diverse methods to observe and estimate surface rainfall amount such as rain gauges, radar and satellite sensors. Rain gauges represent the most direct way for measuring rainfall, however, the spatial coverage of rain gauges in African basins is fairly poor with uneven spatial distribution. Gauges are also limited by their near-point

observations. While weather radar, with continuous spatial coverage, is a decent alternative to rain gauges, a worldwide network of radar stations is unrealistic because of site accessibility, mountain barriers and financial limitations. Therefore, satellite sensors remain the main viable option to observe rainfall for many regions of the world.

Satellite rainfall estimation algorithms commonly rely on either infrared (IR) or passive microwave (PMW) based observations. IR channels measure cloud top temperature, which does not always correlate well with surface rain rates. In addition, rainfall is not necessarily just associated with cold clouds. For PMW based algorithms, estimation biases come mainly from the warm orographic rain, which may not produce much ice aloft. As overland PMW rain retrievals are based mainly on scattering by ice aloft, this may lead to underestimation of surface rain rates. Besides, very cold surfaces and ice over mountain tops could be confused with surface rainfall.

According to Adler et al. (2001), the inter-comparison among different satellite rainfall products clearly establishes the value of merged products using two or more satellite sources. 
For instance, the Tropical Rainfall Measuring Mission (TRMM) Multi-satellite Precipitation Analysis (TMPA) combines precipitation estimates from various satellite systems, as well as land surface precipitation gauge analyses when possible (Huffman et al. 2007). The Precipitation Estimation from Remotely Sensed Information using Artificial Neural Networks (PERSIANN) uses a neural network technique to estimate rainfall rates from IR data (Hsu et al. 1997; Sorooshian et al. 2000). The neural network is calibrated with the TRMM Microwave Imager (TMI), Special Sensor Microwave Imager (SSM/I), and Advanced Microwave Sounding Unit (AMSU) data. The Climate Prediction Center (CPC) morphing technique (CMORPH), developed at the National Oceanic and Atmospheric Administration's (NOAA) CPC (Joyce et al. 2004), uses motion vectors derived from infrared images to fill gaps in MW based rain rates that are derived from multi-satellite MW observations.

Many studies have compared the performance of different satellite rainfall products (Haile et al., 2013; Habib et al., 2012), but none of the studies offer a definite decision on which single product can be considered ideal for detecting the wide range of rain rates in different regions of the world. Mountainous regions have relatively warm clouds, and the thermal IR thresholds commonly used to discriminate between raining and non-raining clouds could cause the IR rainfall retrieval algorithms to miss light-precipitation events (e.g., Hong et al. 2007) or to underestimate total rainfall (e.g., Bitew and Gebremichael 2010). Clouds over mountainous regions could produce heavy rainfall without much ice aloft, which could lead to rainfall underestimation in passive MW algorithms. Therefore rainfall retrieval algorithms, including CMORPH, TMPA and PERSIANN, that use information from a combination of IR, passive MW, and active MW sensors are subject to several error sources in mountainous regions and elsewhere. 
Barros et al. (2006) found that TRMM's precipitation radar has difficulties in detecting precipitation over regions with high elevations. Hong et al. (2007) evaluated the impact that topography might have on the performance of PERSIANN-CCS over the Sierra Madre Occidental (SMO) in western Mexico and found that the bias was affected by the topography. Their study showed that light precipitation events were underestimated at higher elevations and that precipitation at lower elevations was overestimated. Over the Tibetan Plateau, Yin et al. (2008) compared the real time (RT) version of TMPA 3B42 against rain gauge observations and reported that the product overestimated rainfall in this mountainous region. In the mountainous western region of the United States, Gottschalck et al. (2005) found that 3B42RT and PERSIANN-CCS overestimated precipitation. The performance of TMPA 3B42 and CMORPH shows large difference in capturing the temporal rainfall pattern and extremes events in the Philippines (Jamandre and Narisma, 2013). Dinku et al. (2007) selected a large area in Ethiopia, covering both mountainous and flat regions, and compared TMPA and CMORPH precipitation estimates with operational rain gauge observations. They reported lumped statistics for the region of satellite precipitation products versus rain gauge observations: correlation coefficients of 0.46 for 3B42RT and 0.60 for $\mathrm{CMORPH}$, and bias ratios of 1.13 for 3B42RT and 1.11 for CMORPH. Hirpa et al. (2010) performed an evaluation of CMORPH, PERSIANN and TMPA 3B42RT within the Awash River Basin of Ethiopia and found elevation-dependent trends, with underestimation at higher elevations for CMORPH and TMPA 3B42RT. Bitew and Gebremichael (2010) found that CMORPH and PERSIANN-CCS underestimated total rainfall over the high elevation region of the Ethiopia Highlands: CMORPH by $32 \%$ and PERSIANN-CCS by $49 \%$. Compared to TMPA and PERSIANN, CMORPH has smaller rainfall bias and relatively higher correlation with observed rainfall 
amounts.

The accuracy of satellite-rainfall products is also affected by several factors that relate to sampling and retrieval of rain rates (e.g., Gebremichael et al. 2004 and Durden et al. 1998). It is therefore necessary to assess the contributions of each source of uncertainties in satellite rainfall products before these products are used for operational applications. However, validation data sets are limited in terms of both coverage and quality and the few validation studies suggest that products often only perform well in certain locations or situations. For these reasons, there is great difficulty in unambiguously identifying a certain product as "best" in terms of precipitation amount and rate over most of the globe (see Adler et al. 2001). A fairly reliable way to evaluate the accuracy of satellite products is to compare the results with the "true" surface rainfall distribution and intensity, which are usually represented by gauge-based gridded rainfall fields (e.g. Lo Conti et al., 2014). Rain gauges provide near-point observations which can lead to significant errors in estimating area-averaged rain rates while satellite products provide estimates of area-average rain rates but lack accuracy. So, comparing the two data sources of surface rainfall can be challenging. For example, it is sometimes the case that satellite products observe precipitation in the area surrounding a rain gauge while it is not raining at the gauge itself. On the other hand, localized high rain rates observed by gauges might not be shown in satellite estimates which are averaged over its pixel size (e.g., $0.25^{\circ} \mathrm{x}$ $0.25^{\circ}$ ) resulting in lower rain rates than observed by a single gauge. Therefore, it is necessary to improve the averaging methods that make the best use of the features of each observing system in order to better compare these different types of observations (Bowman 2005).

In this study, we will focus on evaluation of the CMORPH rainfall product at its highest spatial resolution $\left(8 \times 8 \mathrm{~km}^{2}\right)$ and at daily time scale. The daily time scale is selected since it is 
the finest resolution at which the rain gauge observations in the study area are operationally collected. The reference rainfall observations are obtained from a gauge network of 25 gauge stations located in the Lake Tana basin. We calculated a set of error metrics (correlation coefficient, standard deviation, bias and its three components) that provide relevant information about the accuracy of CMORPH rainfall product. The study area has complicated topography and land-surface features (mountains, flat areas, large lakes). The results of this study will contribute to the future development of CMORPH products not only in the Lake Tana basin but also in other similar basins; the study will also inform users of this rainfall product about its accuracy.

\section{Study area and data sets}

\subsection{Study area}

Lake Tana, located in the north-west highland in Ethiopia at $12^{\circ} \mathrm{N}, 37.15^{\circ} \mathrm{E}$, is the source of Blue Nile River. The lake is located in a wide depression of the Ethiopian Plateau and has an average elevation of 1,788 $\mathrm{m}$. Lake Tana is the largest lake in Ethiopia and the third largest in the Nile Basin. Its hydrologic basin covers a large domain $\left(10.95^{\circ} \mathrm{N} \sim 12.78^{\circ} \mathrm{N}, 36.89^{\circ} \mathrm{E} \sim\right.$ $38.25^{\circ} \mathrm{E}$ ), a total area of $16,500 \mathrm{~km}^{2}$, of which the lake covers $3,060 \mathrm{~km}^{2}$ (Fig. 1). The lake surface to its basin area ratio is approximately 1:5. Lake Tana has a mean depth of $9 \mathrm{~m}$ and reaches a maximum depth of up to $14 \mathrm{~m}$.

Seasonal rainfall distribution in the Lake Tana basin is controlled by three main factors: the Inter Tropical Convergence Zone (ITCZ) that determines the wet season rainfall distribution; the Saharan anticyclone that generates dry warm north-easterly winds during the dry season; and the Arabian heights that produce thermal lows during the mild season (see Conway 2000). 
Generally, annual rainfall in the basin has a decreasing trend from north to south. At fine time scales (daily and sub-daily), rainfall distribution in the basin is influenced by the presence of Lake Tana and terrain (elevation and aspect). Rainfall is greatest over the mountains in the south, decreases in between the mountains and the lake areas and then increases again towards the lake. Haile et al. (2009) showed that mountain areas in the southern part of the basin receive their maximum rainfall amount in the afternoon since day-time lake breezes diverge from lakes to the warmer surrounding land. In the same work, it is shown that the lake and its south shore receive their maximum rainfall amount in the evening and early morning local hours since night-time land breezes converge towards the warmer central part of the lake.

\subsection{Data sets}

In the present study, we will evaluate the satellite-rainfall product from the Climate Prediction Center (CPC) morphing technique (CMORPH) which is produced at the National Oceanic and Atmospheric Administrations (NOAA) CPC (Joyce et al. 2004). The CMORPH product is available at a temporal frequency of 30 minutes and a spatial resolution of $8 \times 8 \mathrm{~km}^{2}$. The CMOPRH product will be evaluated using surface observations from a network of daily rain gauges located within the Lake Tana Basin and operated by the Ethiopian Meteorological Agency. Based on the availability of the gauge observations from the network, a period of 48 months (January 2003 - December 2006) was selected as the analysis period. We have some doubts on the exact location of Abay Sheleko as obtained from the NMA branch office in Bahir Dar but still included it in our analysis. Therefore the results at this station need to be interpreted with caution.

\section{Methods}


In the present study, the "standard" CMORPH product is evaluated using independent daily surface observations from rain gauges distributed over the study area (Fig. 1). Other versions of CMORPH, the real time QMORPH and the gauge integrated CMORPH, are not evaluated in this study. Graphical comparisons of CMORPH and gauge values for individual stations are presented in the form of scatter plots and bar charts of daily and monthly accumulations. In addition to the graphical comparisons, CMORPH estimates were evaluated using several statistical metrics. To avoid the effect of very low rainfall values that may be introduced by the interpolation of gauge observations, statistics were calculated using Gauge-CMORPH pairs with the condition that at least one of them reported more than $1 \mathrm{~mm} /$ day. The first and most basic statistical metric considered in this study is the total bias, which is defined as follows:

Total Bias (TB) $=\frac{\overline{R_{C M O R P H}-R_{\text {Gauge }}}}{\overline{R_{\text {gauge }}}} \mid\left(R_{\text {CMORPH }}>1\right.$.or. $\left.R_{\text {Gauge }}>1\right)$

where $\mathrm{R}_{\mathrm{CMORPH}}$ and $\mathrm{R}_{\text {Gauge }}$ denote rain amounts from $\mathrm{CMORPH}$ and gauges, respectively. The total bias represents a summary statistic aggregated over the entire data set. Assessment of sources of the total bias helps to gain additional insight into the performance accuracy of CMORPH. Following Tian et al. (2009) and Habib et al. (2009), we also decomposed the total bias into three components: Hit Bias (HB), Missed-Rain Bias (MB) and False-Rain Bias (FB):

Hit Bias $(\mathrm{HB})=\frac{\overline{R_{\text {CMORPH }}-R_{\text {Gauge }}}}{\overline{R_{\text {Gauge }}}} \mid\left(R_{\text {CMORPH }}>1 \& R_{\text {Gauge }}>1\right)$

Missed-Rain Bias (MB) $=\frac{\overline{R_{C M O R P H}-R_{\text {Gauge }}}}{\overline{R_{\text {gauge }}}} \mid\left(R_{\text {CMORPH }} \leq 1 \& R_{\text {Gauge }}>1\right)$

False-Rain Bias $(\mathrm{FB})=\frac{\overline{R_{\text {CMORPH }}-R_{\text {Gauge }}}}{\overline{R_{\text {gauge }}}} \mid\left(R_{\text {CMORPH }}>1 \& R_{\text {Gauge }} \leq 1\right)$ 
The HB refers to the total difference between CMORPH estimates and the reference gauge values when both detect rainfall ( $>1 \mathrm{~mm} /$ day). The MB refers to the total rainfall reported in the gauge dataset when the CMORPH rainfall product does not report rainfall. The FB refers to the total amount of falsely detected rainfall by CMORPH. The value of the three bias components adds up to the total bias. Note that the divisor of equations $2-4$ is the same as the total observed rainfall amount without applying threshold is used.

In addition to the bias, two more statistical metrics were used to evaluate the CMORPH product: the standard deviation of differences between $\mathrm{R}_{\mathrm{CMORPH}}$ and $\mathrm{R}_{\text {Gauge, }}$, which was used to assess the random error in the CMORPH product, and the correlation coefficient which was used to measure the linear association between CMORPH estimates and the corresponding gauge observations. To examine any possible spatial dependency in the CMORPH accuracy, these statistics were calculated and presented in the form of grid based spatial maps. Observations from individual gauges were interpolated using inverse distance weighing method onto the same grid as CMORPH and the statistics calculated for each grid pixel. The spatial maps are important to show spatial patterns of CMORPH performance; however, these maps should be interpreted with care as the rain gauges are unevenly distributed across the study area. Note also that the microwave products are based on different retrieval schemes over water versus over land. As such the accuracy of the CMORPH rainfall estimates over the islands and shores of the lake could possibly be affected by the type of retrieval scheme.

\section{Results}

\subsection{Seasonal and Monthly Rainfall Distributions}


The agreement between gauges and $\mathrm{CMROPH}$ is assessed at a number of representative stations distributed over the basin (Fig. 2 and Fig. 3). Based on the gauge observations, monthly rainfall distributions over the basin vary spatially and from one month to another. Here we note that the wet season is defined from June to September and the remaining months are defined as Dry Season. Sekela, located on the mountain in the southern part of the basin, has the largest seasonal rainfall amount especially during the wet season, which could be attributed to its high altitude. Rainfall enhancement by Lake Tana also resulted in relatively large rainfall amounts at the center of the lake (Deke Istifanos) along the southern shore of the lake (Bahir Dar). Stations in the northern part (Gondar) have a relatively smaller amount of rainfall. While the overall seasonal and spatial pattern of the rainfall is reasonably captured by CMORPH, at least in a qualitative sense, varying degrees of over- and underestimation by CMORPH are observed. CMORPH reproduced monthly rainfall distribution at stations in the northern part (Gondar) with a relatively good agreement to the gauge pattern. At the center of Lake Tana (Deke Istifanos), CMORPH underestimated monthly rainfall amounts during the wet season (except June) and overestimated during the dry season. At the lake shore station (Bahir Dar), it overestimated monthly rainfall except in July. It underestimated monthly rainfall in the eastern part (Debre Tabor) and in the southern part (Wotet Abbay and Sekela) with relatively large differences during the wet season.

A comparison of rainfall occurrence between $\mathrm{CMORPH}$ and gauge observations is shown in Fig. 3. During the dry season, CMORPH mostly overestimates daily rainfall occurrence in the study area. The degree of overestimation is relatively small for most stations situated in the southern part of the basin but becomes large (up to more than twice) over and near the lake. 
Some overestimation is also observed at most stations in the eastern and northern part of the basin. For the wet season, CMORPH reported slightly smaller rainfall occurrence than actually observed over mountain stations in the southern part of the basin (Sekela, Kidamaja, Injibara) but reported slightly more occurrence at stations in between the mountain areas and the lake (Dangila, Wotet Abbay, Adet). Over and near the lake, CMOPRH significantly overestimated rainfall occurrence (by $>25 \%$ ) during the wet season. The results for the eastern part are mixed as occurrence is overestimated at some stations but underestimated at other stations with no clear trend. For the northern part, CMORPH reported significantly more rainfall occurrence than is actually observed.

\subsection{Spatial Patterns in CMORPH Bias}

To gain further insight on possible spatial dependence in the performance of CMORPH product, we examine the spatial distribution of daily average rainfall over the entire basin (Fig. 4). For the dry season, the spatial pattern of mean daily rainfall from CMORPH and gauges shows large differences. CMORPH shows large rainfall amounts in areas where gauges reported small amounts and vice versa. This applies to other parts of the basin as well. For the wet season as well, the spatial pattern of mean daily rainfall from CMORPH and gauges shows large differences. The increasing trend in rainfall amount that stretches from the southern mountains towards the lake is not captured by CMORPH. In the

north, similarly, CMORPH is not able to capture the daily rainfall pattern. In the eastern part, CMORPH shows a larger spatial gradient of daily rainfall amount than that by gauges.

Next, the spatial distribution of CMORPH bias and its three components (Equations 1-4) are examined separately for the wet and dry seasons. Fig. 5 shows the biases in the wet season using spatial maps. The figure shows that total bias has a decreasing trend stretching 
from the mountain areas towards the lake suggesting elevation dependence. The observed rainfall amount in the eastern and southern parts of the basin is underestimated (by up to -25 and $-15 \%$ respectively) and overestimated over the western and northern parts (by up to 35 and 5\%), respectively. The spatial pattern of hit bias is similar to the pattern of total bias. It divides the basin east vs west with underestimation over the eastern part and overestimation over the western part of the basin, and near zero hit bias over the lake. The missed bias has a decreasing trend stretching from the northern and northwestern parts (-10 to $-15 \%)$ to the southern part. Bias due to false-rain is much small over most of the basin and doesn't exceed $5 \%$.

The dry season rainfall is overestimated over most parts of the basin (Fig. 6). Maximum overestimation was found for the southern part of the basin (up to 60\%). Total bias is relatively negligible for most of the eastern part but slightly increases towards the eastern shore of the lake. Over the lake, the total bias shows a large variation with small bias values stretching from north to south showing favorable performance. However, large biases exist in the eastern and western parts of the lake (up to $60 \%$ ). Most of the bias in the dry season is contributed by the hit-bias component, which has a clear spatial variation. There is also similarity in the spatial patterns of total and hit biases which have values that decrease from the mountain areas towards the lake. Missed bias has relatively small variations across the Lake Tana basin; its smallest values occur over the southern part of the basin with highest values over the lake and the western and eastern parts of the basin (-40 to $-60 \%)$. The spatial pattern of the missed rainfall bias is similar to that of the hit bias except that it shows a more pronounced variation as indicated by the closely spaced contours over the lake. Unlike the wet season, the false-rain bias component in the dry season 
attains considerably high values (15-45\% with few isolated areas having up to $65 \%$. The mountains in the eastern and northern parts have the smallest missed bias $(\sim 15 \%)$.

\subsection{Assessment at Daily Scale}

Daily CMORPH and gauge data are compared visually using scatter plots of daily rainfall depth over six selected stations distributed across Lake Tana basin (Fig. 7). The six stations cover different parts of the basin: northern, eastern and southern, as well as the southern shore and an island on the lake. The visual comparison of daily rainfall amounts shows significant scatter with several instances of both over- and underestimation. Several points are spread along the $\mathrm{x}$-axis indicating that CMORPH missed several rainy days $\left(\mathrm{R}_{\mathrm{CMORPH}}=0\right.$ and $\left.\mathrm{R}_{\mathrm{G}}>0\right)$. These missed rain amounts are mostly within $0<\mathrm{R}_{\mathrm{G}}<25 \mathrm{~mm}$ but also exceed $25 \mathrm{~mm}$ in some instances particularly at Sekela which is situated on the southern mountains of the basin. Similarly, there are many data points spread along the y-axis indicating false rainy days $\left(\mathrm{R}_{\mathrm{CMORPH}}>0\right.$ and $\left.\mathrm{R}_{\mathrm{G}}=0\right)$. These false rainfall amounts are mostly within 0-25 mm with larger false rainfall amounts not uncommon over Lake Tana (Deke Istifanos) and south of the lake (Wotet Abbay).

A quantitative assessment at the daily scale is obtained using two statistical metrics: correlation coefficient, which measures the degree of linear relation, and standard deviation of differences, which measures the spread in the random error. The correlation coefficient between CMORPH and gauge varies spatially and seasonally over the Lake Tana basin (Fig. 8). The linear relationship between the two rainfall datasets in the dry season is apparently weaker (mostly $<0.4)$ than that in the wet season (mostly $>0.4)$. In the wet season, the correlation coefficients over most parts of the basin indicate a moderately strong relationship (0.4-0.6). The correlation is stronger $(>0.5)$ in the northern part of the basin that receives the smallest rainfall 
amount (around Gondar), the northeastern and eastern part of the lake, and near the southwest of the lake. There is very weak correlation $(0.2 \sim 0.3)$ on the south shore of the lake and south part of the basin where the largest rainfall amount in the basin is received.

The standard deviation of CMORPH-gauge differences was calculated to quantify the random error in the CMORPH product. The spatial distributions (Fig. 9) of the standard deviation of daily rainfall differences on annual and seasonal scales have some similarities. The smallest standard deviation values occur over the eastern mountains and over the northern part of the basin. The largest values mostly occur around the south shore of Lake Tana. The dry season has the lowest random differences (mostly $<9 \mathrm{~mm} / \mathrm{d}$, which is twice the mean daily rainfall amount). In the wet season, the random differences do not exceed the mean daily rainfall amounts over the basin.

\section{Conclusion}

The objective of this study was to assess the accuracy of the CMORPH satellite-rainfall product over the Lake Tana basin in Eastern Africa. This basin is the source of the Blue Nile and represents a prime example of many world regions that can benefit greatly from satellite-based rainfall products. The assessment is conducted at the highest spatial resolution of the product $\left(8 \times 8 \mathrm{~km}^{2}\right)$ and at several temporal scales (daily, monthly, seasonal and annual) for a period covering January 2003 to December 2006. The assessment is made possible through the use of an independent set of rain gauges available in the region and used as an evaluation reference. We utilized graphical techniques and several statistical metrics to examine the product accuracy. Results, which are displayed in terms of spatial maps, should be interpreted with care particular for parts of the basin where there are few or no rain gauges. Issues related to gauge representativeness in the study area are addressed in our previous work 
(Haile et. al., 2013).

The following conclusions can be made based on the results of the current analysis:

1. CMORPH better captures daily rainfall occurrences than rainfall amounts over the Lake Tana basin. However, both dry and wet season rainfall occurrences are overestimated over the northern part of the basin as well as over the lake and its islands and shore.

2. The bias of CMORPH in the study area is characterized by seasonal and spatial variations (-25 to $30 \%$ in wet season and -40 to $60 \%$ in dry season). These bias values are slightly larger than the biases of CMORPH that are reported by Bitew and Gebremichael (2010) for humid tropical region in Ethiopia. In the wet season, the largest bias is observed over western parts (overestimation) and eastern parts (underestimation) of the basin. The total bias of the wet season decreases when approaching the lake and as elevation decreases. Hirpa et al. (2010) also reported that CMORPH performance is elevation dependent over the Awash basin of Ethiopia. Dry season rainfall amounts are overestimated over southern and western part of the basin and over the lake. Dry season rainfall over the mountainous areas experienced the largest overestimation of rainfall amount, with the exception of the eastern part of the basin.

3. Hit bias is the dominant contributor to the total bias of CMORH (-30 to $30 \%$ in wet season and 10 to $70 \%$ in dry season). However, there are some exceptions where the false bias becomes most significant. The false bias is very small in the wet season $(<5 \%$ in most areas) but becomes significant (15-90\%) in the dry season. CMORPH reports false daily rainfall amount of up to $75 \mathrm{~mm}$ and missed rainfall amounts in excess of $25 \mathrm{~mm}$. Missed bias (up to $-18 \%$ ) has the largest values over the lake and its surroundings. It shows a decreasing pattern as distance increases from the lake attaining its minimum value over the 
mountains.

4. Significant differences are observed between CMORPH and gauge at the daily resolution of the CMORPH product. The standard deviation of daily rainfall differences of CMORPH and gauge data ranges between 5 to $15 \mathrm{~mm}$ /day in the dry season. The standard deviations are larger in the wet season. CMORPH and gauge daily rainfall amounts show weak to moderate correlations. Higher correlations are observed over the eastern part of the basin and the northern mountains. This relationship is stronger (correlation coefficient $>0.4$ ) in the wet season than in the dry (correlation coefficient $<0.4$ ). The values are somewhat comparable with the results reported for the Ethiopian highlands by Dinku et al. (2007), although our results indicate that the correlation coefficient is season dependent.

5. Overall, there is a distinct difference between the accuracy of CMORPH in the wet and the dry season. It is also observed that the accuracy of CMORPH in the basin shows large spatial variability. However, Habib et al. (2014) showed that accounting for the temporal variability of CMORPH bias has the largest influence on streamflow model simulations for the southern part of the Lake Tana sub-basin and should be taken into account. Gebregiorgis and Hossain, (2013) also suggested the need to factor in spatial and temporal aspects of satellite rainfall bias. Therefore, it is recommended that more effort should be devoted towards applying spatially and temporally-varying bias correction to the CMORPH product and evaluating the implications of such adjustments for water resources applications in the study area. The comparative bias correction algorithms that are used for applications in climate change and radar rainfall studies should be evaluated for correcting rainfall estimates of CMORPH.

\section{Acknowledgment:}


Support for this study was provided by the National Science Foundation (NSF) through Award Number OISE-0914618 to the University of Louisiana at Lafayette, and by the NASA EPSCoR/BoR DART2 program and the NASA Grant to Louisiana Space (LaSPACE) Consortium. Support provided by the University of Louisiana at Lafayette Computational and Visualization Enterprise (CAVE) Consortium is acknowledged. Support for article preparation is also received from the CGIAR Research Program on Water, Land and Ecosystems (WLE) which is led by International Water Management Institute (IWMI). We would like to thank the two anonymous reviewers for their valuable comments and suggestions. 


\section{REFERENCES}

Adler, R.F., Kidd, C., Petty, G., Morissey, M. Goodman, H. M. 2001. Intercomparison of global precipitation products: the Third Precipitation Intercomparison Project (PIP-3). Bull. Amer. Meteor. Soc. 82, 1377-1396.

Barros, A.P., Chiao, S., Lang, T.J., Burbank, D., Putkonen, J. 2006. From weather to climate Seasonal and interannual variability of storms and implications for erosion processes in the Himalaya, Geological Society of America. 398, 17-38

Bitew, M.M., Gebremichael, M. 2010. Evaluation through independent measurements: Complex terrain and humid tropical region in Ethiopia. Satellite Rainfall Applications for Surface Hydrology, M. Gebremichael and F. Hossain, Eds., Springer-Verlag, 205-214.

Bowman, K.P. 2005. Comparison of TRMM precipitation retrievals with rain gauge data from ocean buoys, J. Clim. 18, 178-190, doi: 10.1175/JCLI3259.1.

Conway, D. 2000. The Climate and Hydrology of the Upper Blue Nile River. Geogr. J. 166, 49-62. doi: 10.1111/j.1475-4959.2000.tb00006.x

Dinku, T., Ceccato, P., Grover-Kopec, E., Lemma, M., Connor, S.J., Ropelewski, C.F. 2007. Validation of satellite rainfall products over East Africa's complex topography. Int. J. Remote Sens. 28, 1503-1526

Durden, S.L., Haddad, Z.S., Kitiyakara, A., Li, F.K. 1998. Effects of Nonuniform Beam Filling on Rainfall Retrieval for the TRMM Precipitation Radar. J. Atmos. Ocean Tech. 15, 635-646.

Gebregiorgis, A., Hossain, F. 2013. Document Performance evaluation of merged satellite rainfall products based on spatial and seasonal signatures of hydrologic predictability. Atmos Res, 132-133, 223-238.

Gebremichael, M., Krajewski, W.F. 2004. Characterization of the temporal sampling error in space-time-averaged rainfall estimates from satellites. J. Geophys. Res. 109 (D11), p. D11110, DOI: 10.1029/2004JD004509.

Gottschalck, J., Meng, J., Rodell, M., Houser, P. 2005. Analysis of multiple precipitation products and preliminary assessment of their impact on global land data assimilation system land surface states. J. Hydrometeor. 6(5), 573-598.

Habib, E., Elsaadani, M., Haile, A. T. 2012. Climatology-Focused Evaluation of CMORPH and TMPA Satellite Rainfall Products over the Nile Basin. J. Appl. Meteorol. Clim. 51, 2105-2121.

Habib, E., Haile, A. T., Sazib, N.,Zhang, Y., Rientjes, T. 2014. Effect of Bias Correction of Satellite-Rainfall Estimates on Runoff Simulations at the Source of the Upper Blue Nile. Remote Sens. 6(7), 6688-6708; doi:10.3390/rs60x000x

Habib, E., Larson, B., Graschel, J. 2009. Validation of NEXRAD multisensor precipitation estimates using an experimental dense rain gauge network in south Louisiana. J. Hydrol. 373, 463-478.

Haile, A.T., Habib, E., Rientjes, T.H.M., 2013. Evaluation of the climate prediction center (CPC) morphing technique $(\mathrm{CMORPH})$ rainfall product on hourly time scales over the source of the Blue Nile River. Hydrol. Process. 27, 1829-1839.

Haile, A.T., Rientjes, T.H.M., Gieske, A.S.M., Gebremichael, M. 2009. Rainfall variability over mountainous and adjacent lake areas: the case of Lake Tana basin at the source of the Blue Nile river. J. Appl. Meteorol. Clim. 48, 1696-1717. 
Hirpa, F.A., Gebremichael, M., Hopson, T. 2010. Evaluation of High-Resolution Satellite Precipitation Products over Very Complex Terrain in Ethiopia. J. Appl. Meteorol. Clim. 49, 1044-1051. doi: 10.1175/2009JAMC2298.1

Hong, Y., Gochis, D.J., Cheng, Y., Hsu, K.-L., Sorooshian, S. 2007. Evaluation of PERSIANN-CCS rainfall measurement using the NAME Event Rain Gauge Network. J. Hydrometeor. 8, 469-482.

Hsu, K., Gao, X., Sorooshian, S., Gupta, H.V. 1997. Precipitation estimation from remotely sensed information using artificial neural networks. J. Appl. Meteor. 36, 1176-1190.

Huffman G.J., Adler, R.F., Bolvin, D.T., Gu, G.J., Nelkin, E.J., Bowman, K.P., Hong, Y., Stocker, E.F., Wolff, D.B. 2007. The TRMM multisatellite precipitation analysis (TMPA).Quasi-global, multiyear, combined-sensor precipitation estimates at fine scales. J. Hydrometeor. 8, 38-55.

Jamandre, C.A., Narisma, G.T. 2013. Spatio-temporal validation of satellite-based rainfall estimates in the Philippines. Atmos Res, 122, 599-608.

Joyce, R.J., Janowiak, J.E., Arkin, P.A., Xie, P.P. 2004. CMORPH: a method that produces global precipitation estimates from passive microwave and infrared data at high spatial and temporal resolution. J. Hydrometeor. 5, 487-503.

Lo Conti, F. , Hsu, K.-L. , Noto, L.V., Sorooshian, S. 2014. Evaluation and comparison of satellite precipitation estimates with reference to a local area in the Mediterranean Sea. Atmos Res, 138, 189-204.

Sorooshian, S., Hsu, K., Gao, X., Gupta, H.V., Imam, B., Braithwaite, D. 2000. Evaluation of PERSIANN system satellite-based estimates of tropical rainfall. Bull. Amer. Meteor. Soc. 81: 2035-2046.

Tian, Y., Peters-Lidard, C.D., Eylander, J.B., Joyce, R.J., Huffman, G.J., Adler, R.F., Hsu, K., Turk, F.J., Garcia, M., Zeng, J. 2009. Component analysis of errors in satellite-based precipitation estimates. J. Geophys. Res. 114, D24101, doi:10.1029/2009JD011949.

Yin Z.Y, Zhang, X.Q., Liu, X.D., Colella M., Chen X.L., 2008. An assessment of the biases of satellite rainfall estimates over the Tibetan Plateau and correction methods based on topographic analysis, J. Hydrometeor. 9(3), 301-326 


\section{LIST OF FIGURES}

Fig. 1. Study site of the Lake Tana Basin, Ethiopia, showing the locations of daily rain gauges (represented by circles). The grey color scale represents elevation over the basin....

Fig. 2. Bar plots of gauge and CMORPH monthly rainfall in different stations of Lake Tana Basin based on the period 2003-2006.

Fig. 3. Bar plots of CMORPH and gauge rainfall occurrence (\%) in different Stations of Lake Tana Basin (shown on X-axis). Stations are defined as follows: (TL: Tilli; KD: kidamaja; SK:sekela; IJ:Injibara DG:Dangila; WA:Wotet Abbay; AD:Adet; AS:Abbay Sheleko; KM: Kimbaba; BD: Bahir Dar; ZE:Zege; DI: Deke Istifanos; YF:Yifag; AG: Arb Gebeya; WZ:Wanzaye; WO:Woreta; AB:Amed_Ber; DT:Debre Tabor; GS:Gassay; IB:Ibnat; AZ:Addis Zemen; EF:Enfranz; DG:Delgi; AY:Aykel; GD:Gandar)............... 22

Fig. 4. Spatial maps of gauge and CMORPH mean daily rainfall amounts. .......................... 23

Fig. 5. Decomposition of total CMORPH bias in wet season into its three components. The percentage of the bias components to the total rainfall depth is shown on the contour lines.

Fig. 6. Decomposition of total bias in the dry season into its three components. Contour values indicate the percentage of bias components to the total rainfall depth. 25

Fig. 7. Scatter plots of daily CMORPH rainfall amounts versus the corresponding gauge values over six rain gauges from different parts of Lake Tana basin.

Fig. 8. Spatial maps of the correlation coefficient between daily CMORPH and gauge rainfall.

Fig. 9. Spatial maps of the correlation coefficient between daily CMORPH and gauge rainfall. 28 


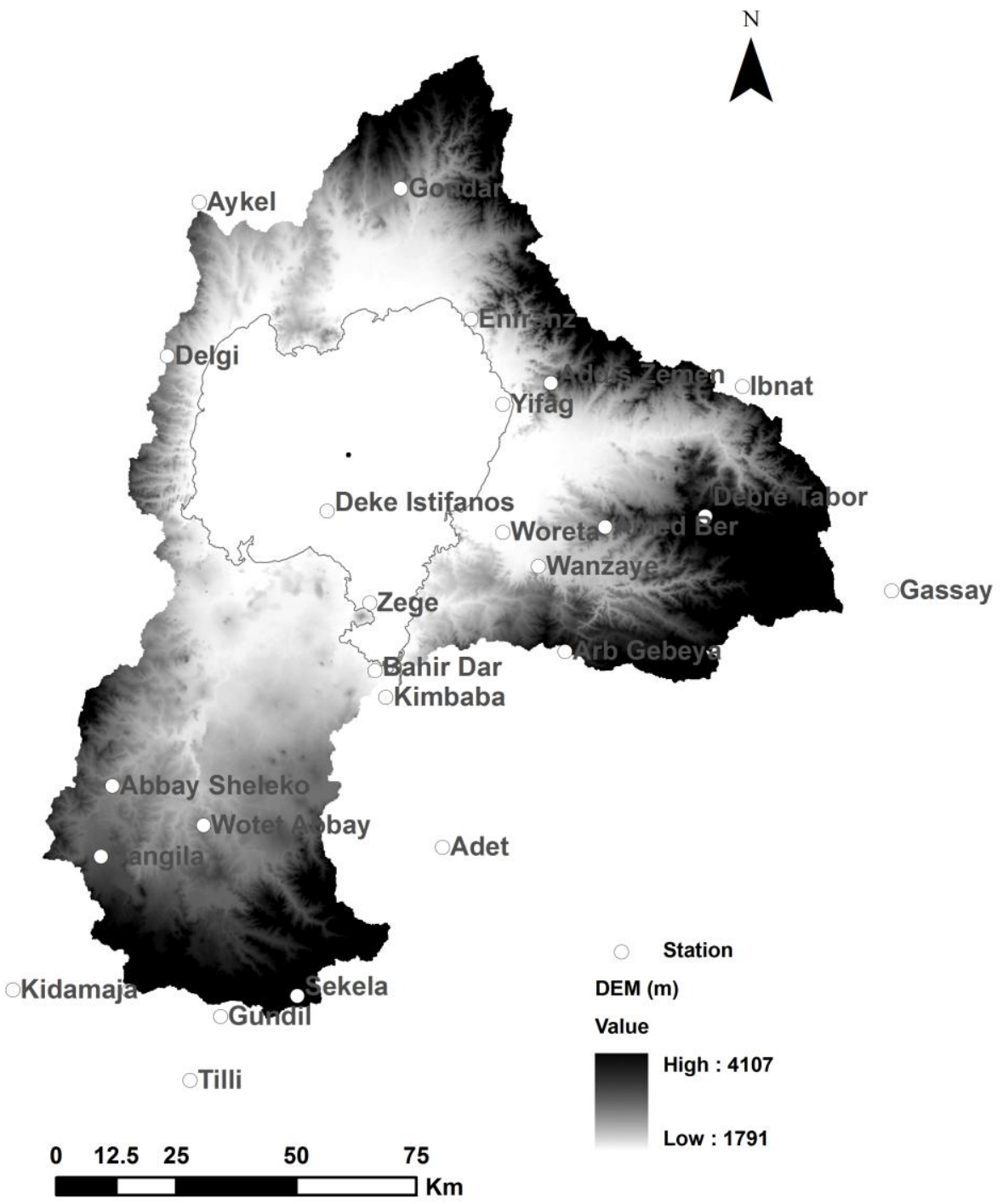

Fig. 1. Study site of the Lake Tana Basin, Ethiopia, showing the locations of daily rain gauges (represented by circles). The grey color scale represents elevation over the basin. 

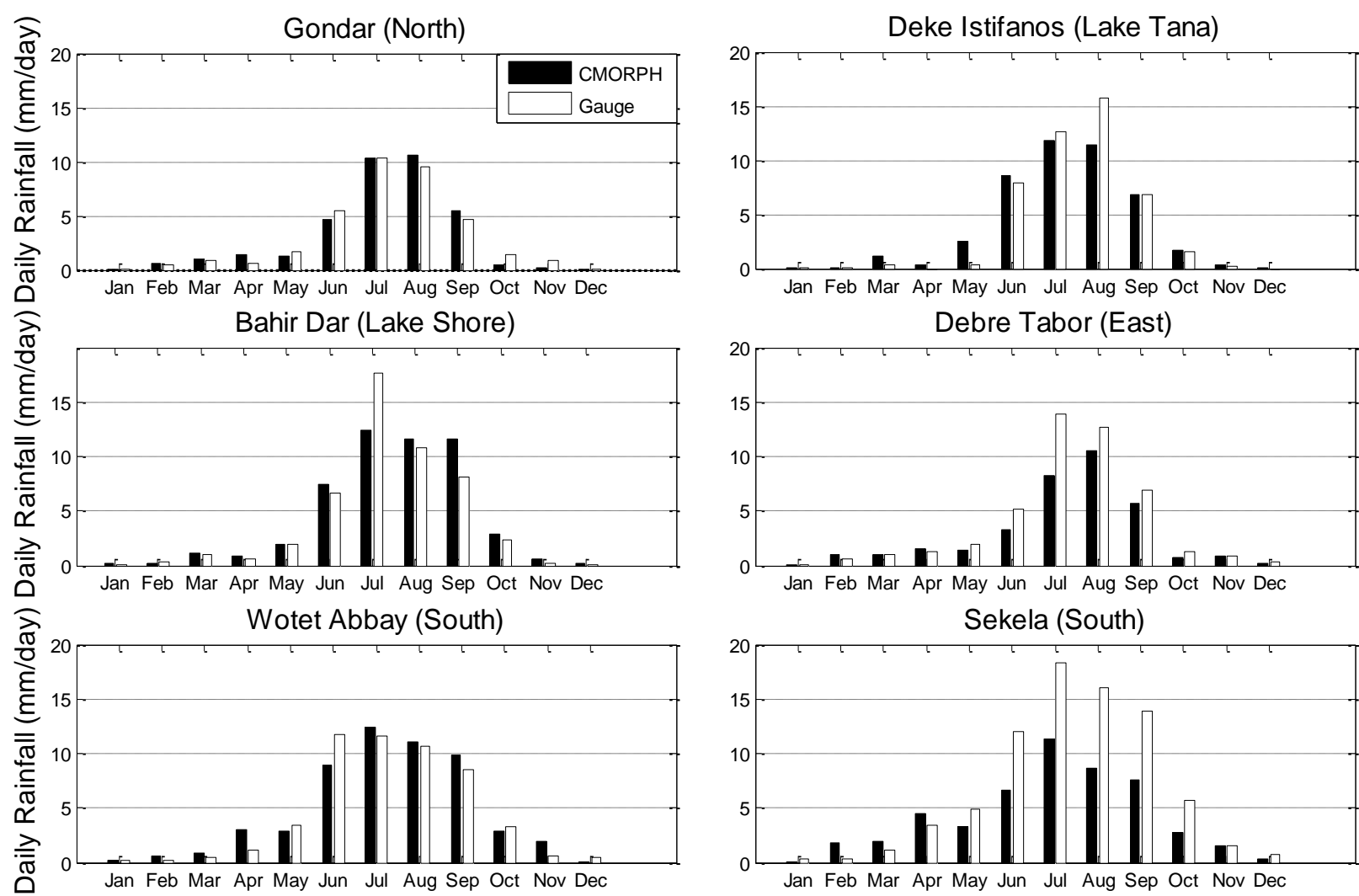

Debre Tabor (East)

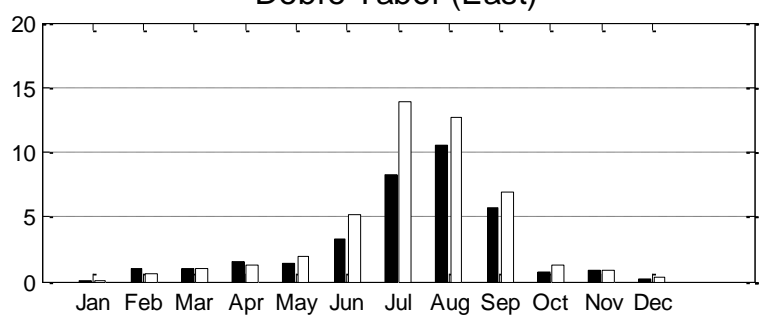

Sekela (South)

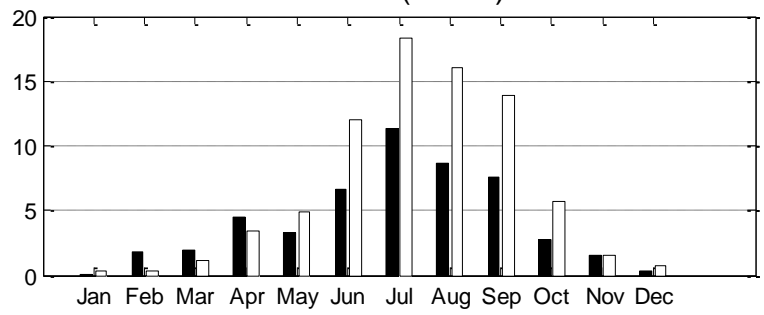

Fig. 2. Bar plots of gauge and CMORPH monthly rainfall in different stations of Lake Tana Basin based on the period 2003-2006. 

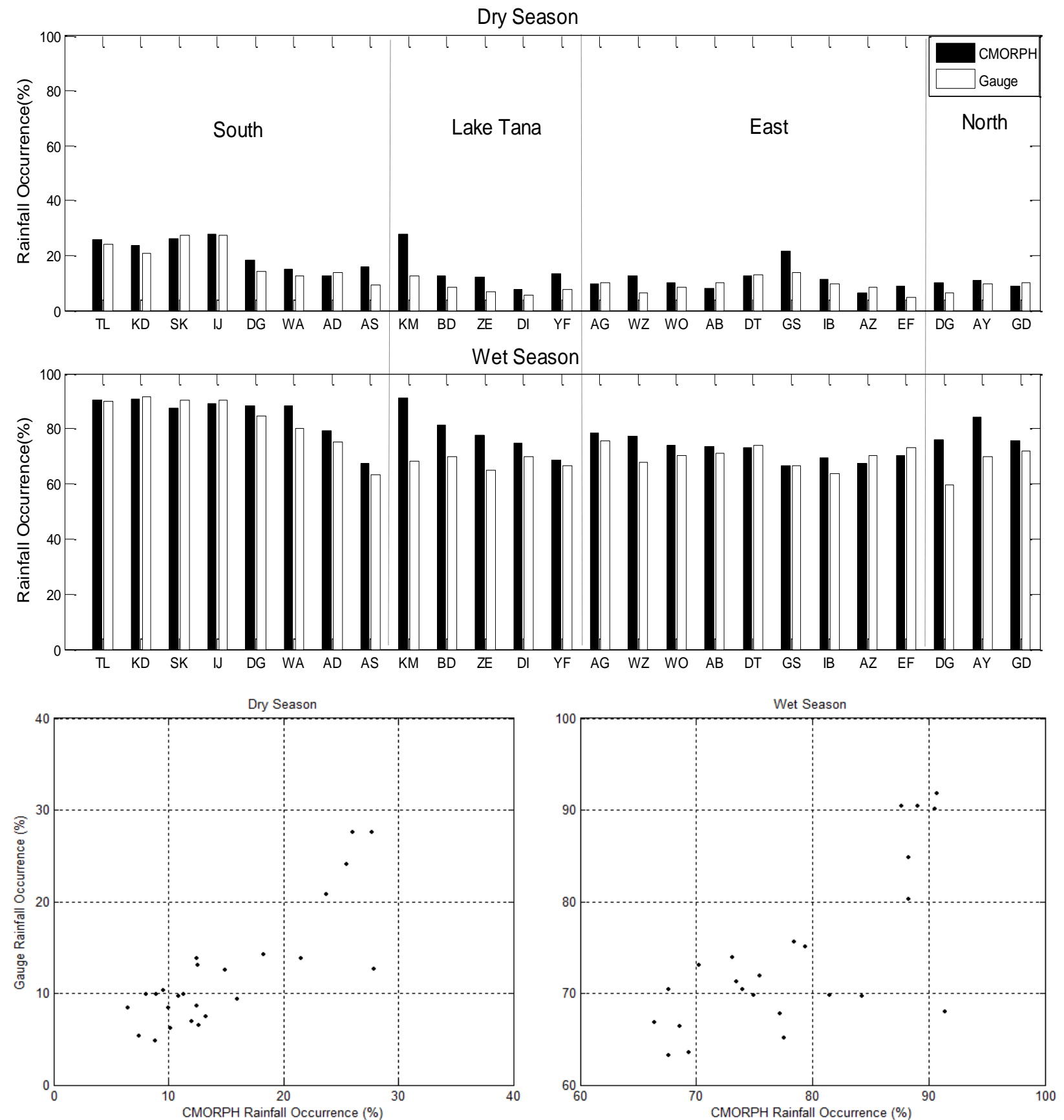

Fig. 3. Bar plots of CMORPH and gauge rainfall occurrence (\%) in different Stations of Lake Tana Basin (shown on X-axis). Stations are defined as follows: (TL: Tilli; KD: kidamaja; SK:sekela; IJ:Injibara DG:Dangila; WA:Wotet Abbay; AD:Adet; AS:Abbay Sheleko; KM: Kimbaba; BD: Bahir Dar; ZE:Zege; DI: Deke Istifanos; YF:Yifag; AG: Arb Gebeya; WZ:Wanzaye; WO:Woreta; AB:Amed_Ber; DT:Debre Tabor; GS:Gassay; IB:Ibnat; AZ:Addis Zemen; EF:Enfranz; DG:Delgi; AY:Aykel; GD:Gandar). A scatter plot of CMORPH-Gauge rainfall occurrence is also shown. 

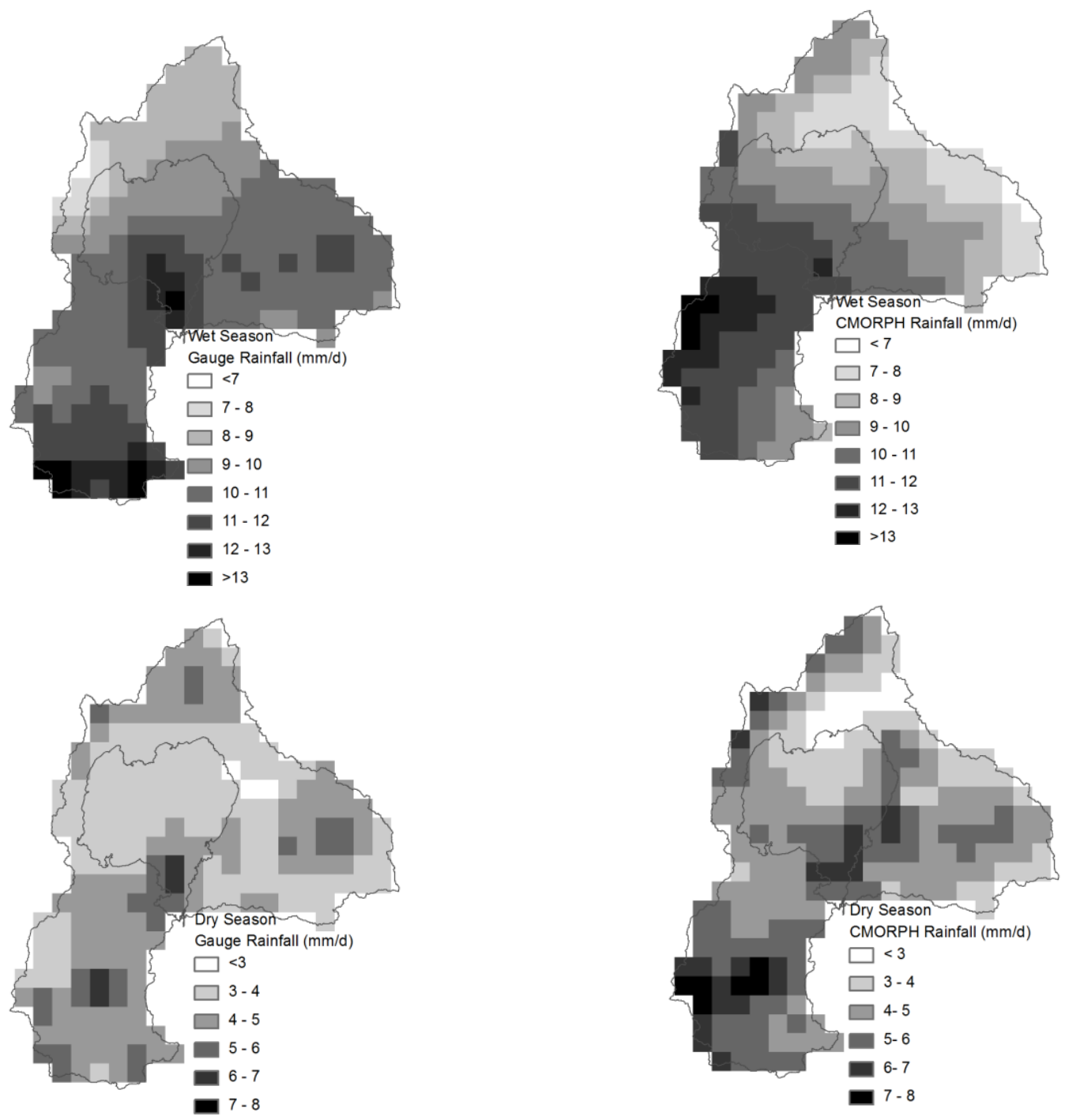

Fig. 4. Spatial maps of gauge and CMORPH mean daily rainfall amounts. 

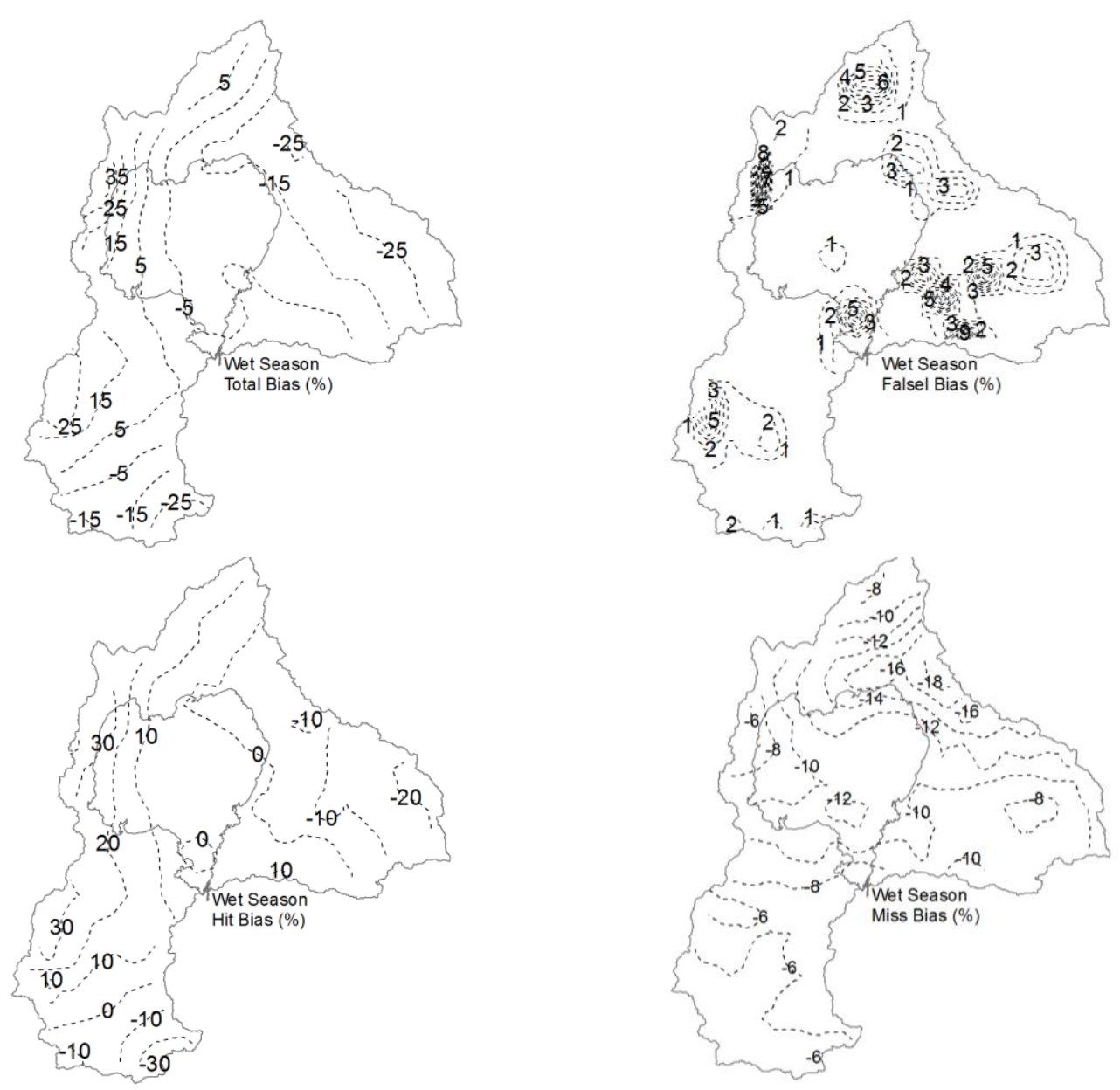

Fig. 5. Decomposition of total CMORPH bias in wet season into its three components. The percentage of the bias components to the total rainfall depth is shown on the contour lines. 

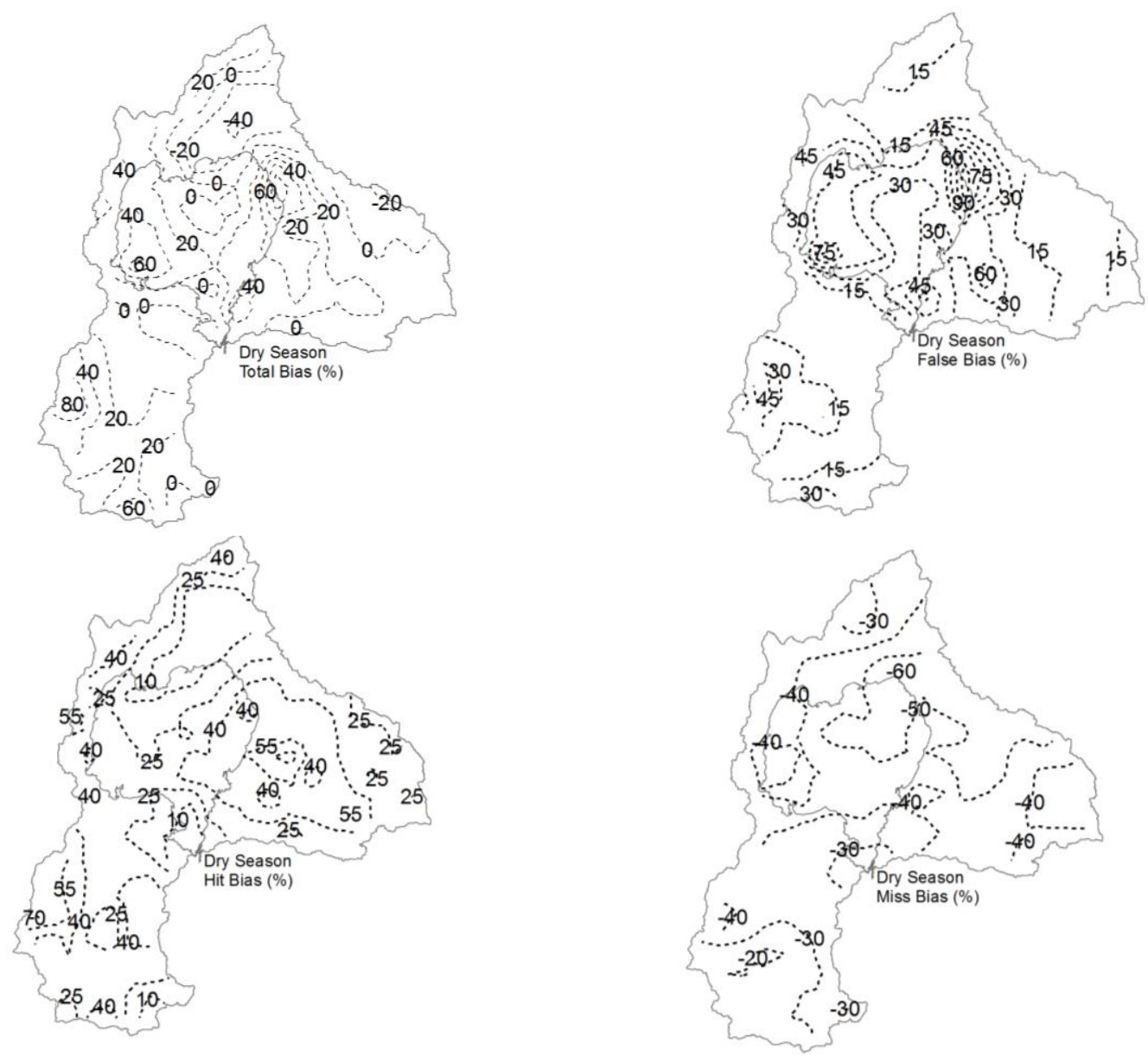

Fig. 6. Decomposition of total bias in the dry season into its three components. Contour values indicate the percentage of bias components to the total rainfall depth. 

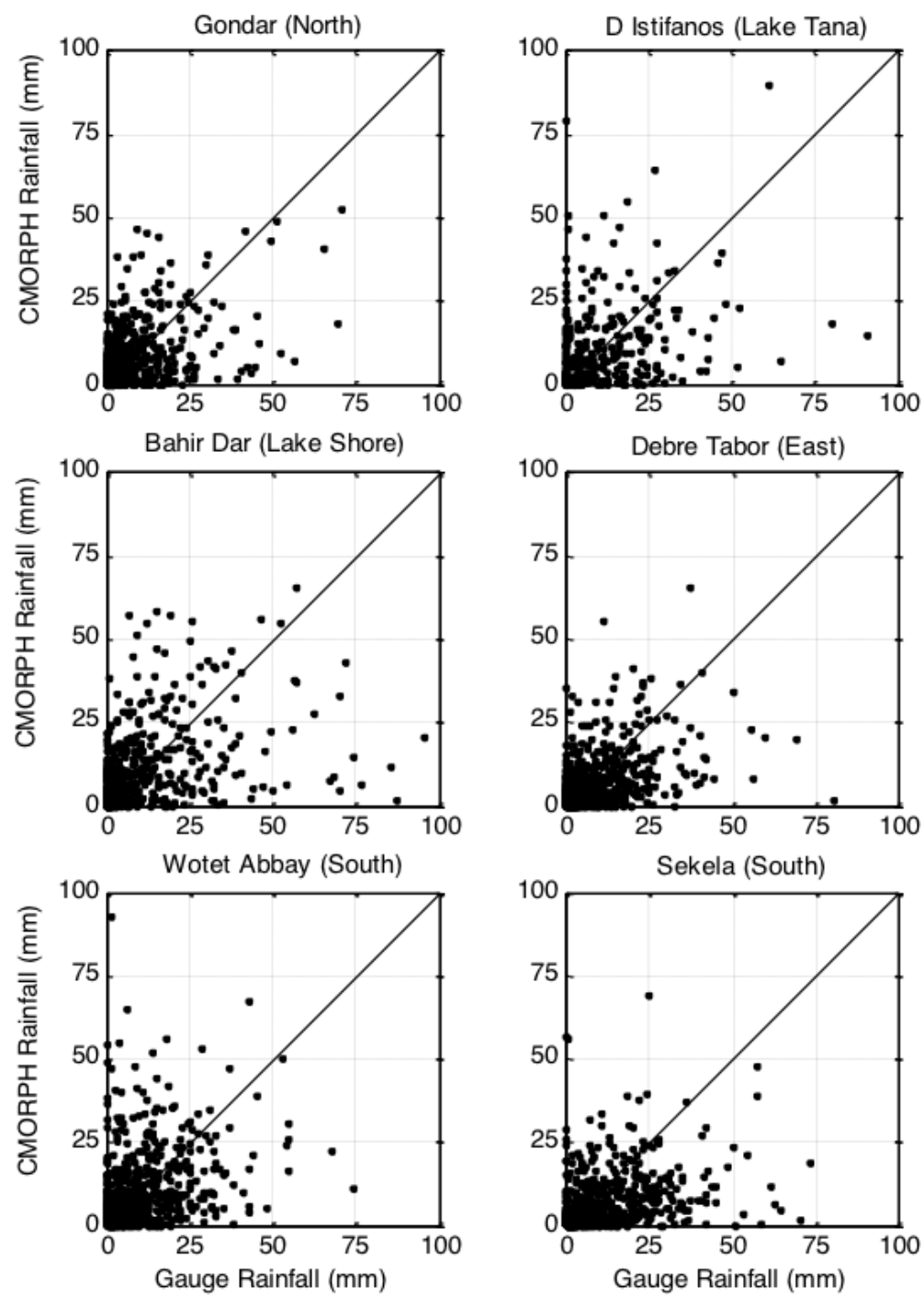

Fig. 7. Scatter plots of daily CMORPH rainfall amounts versus the corresponding gauge values over six rain gauges from different parts of Lake Tana basin. 

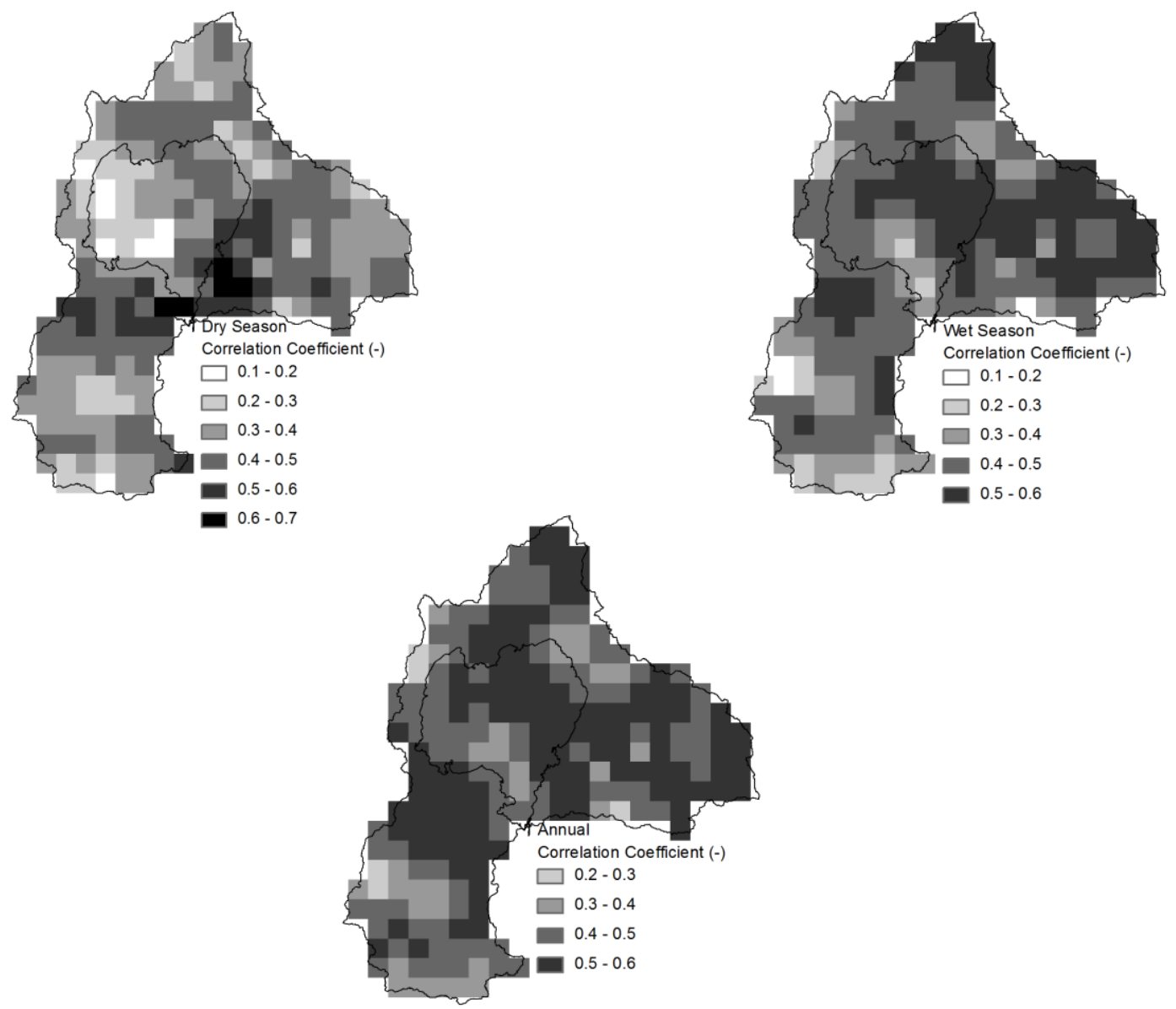

Fig. 8. Spatial maps of the correlation coefficient between daily CMORPH and gauge rainfall. 


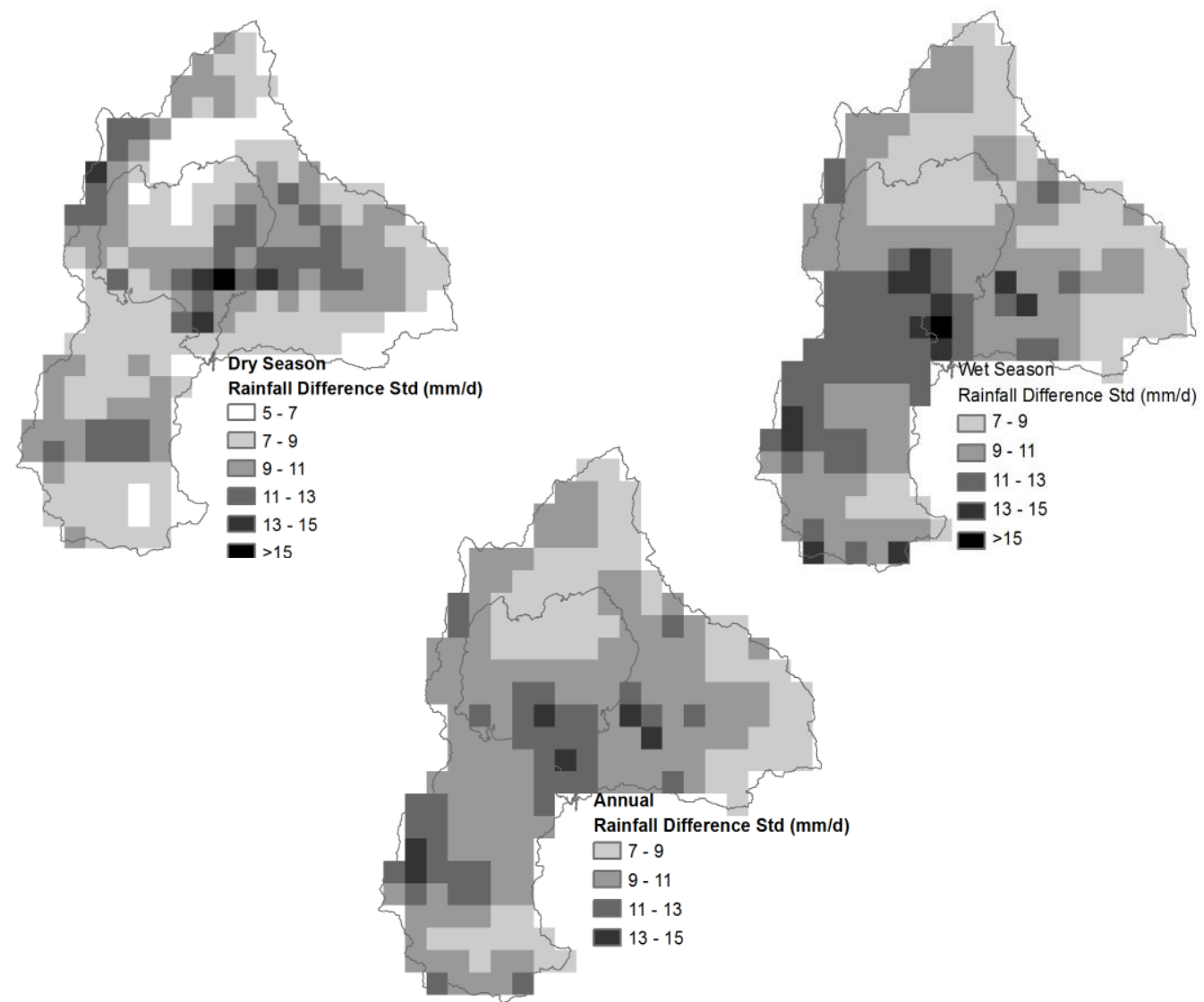

Fig. 9. Spatial maps of the standard deviation of rainfall difference between daily CMORPH and gauge rainfall. 